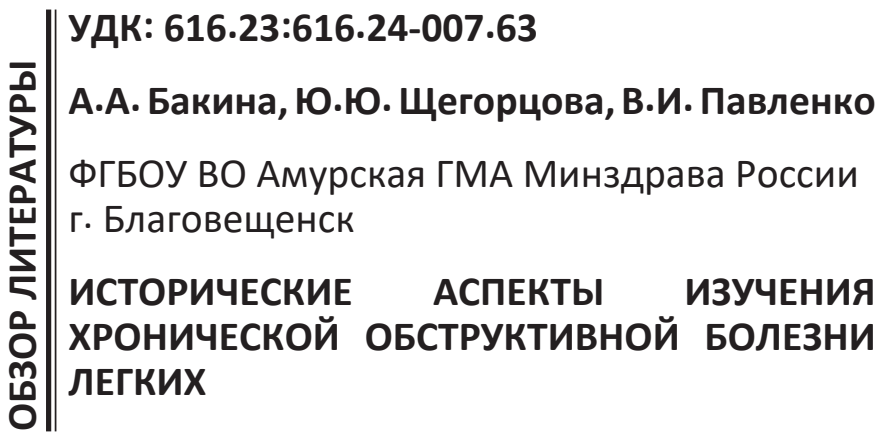

Хроническая обструктивная болезнь легких (ХОБЛ) - «распространенное заболевание, характеризующееся персистирующими симптомами и ограничением воздушного потока, связанными с аномалиями дыхательных путей и/или альвеол, причиной которых обычно является значительное воздействие раздражающих частиц или газов; однако ХОБЛ можно предотвратить и лечить» [2]. ХОБЛ является важной проблемой медицины современности. Эпидемиологическое исследование GARD показало, что 15,3\% населения в Российской Федерации имеют диагноз ХОБЛ [15]. Lozano R (2012) в своих исследованиях отмечает, что ХОБЛ может подняться на 3-е место среди заболеваний, являющихся причинами смерти, после сердечно-сосудистой и цереброваскулярной патологий уже к 2030 году [21]. Ввиду широкой распространенности ХОБЛ с 2003 года по инициативе Всемирной организации здравоохранения (ВО3) и Глобальной инициативы по борьбе против ХОБЛ в каждую третью среду ноября отмечается Всемирный день борь- бы против ХОБЛ (World COPD Day). Исторически понятие ХОБЛ претерпевало множество изменений. Изменялись терминология и определение заболевания, порой мнения об этиологии и патогенезе являлись диаметрально противоположными. Наиболее активно процесс изучения ХОБЛ начался в XX веке и интерес к данной проблеме не угасает по сегодняшний день.

Легочные заболевания всегда являлись одной из основных причин заболеваемости и смертности населения. Первые представления о наиболее часто встречающихся заболеваниях легких начали формироваться уже в древности. Однако в течение большого количества времени они были эмпирическими, лишенными научной основы. Лишь в работах У. Гарвея отмечается верное представление о функции легких и сущности расстройств при различных видах легочной патологии. Хронические медленно прогрессирующие бронхолегочные заболевания воспалительной природы, сочетающиеся с нарушениями вентиляции по обструктивному типу, имеют непростую историю изучения. Наиболее ранние описания ХОБЛ встречаются как описания отдельных клинических и патоморфологических элементов патологии. Так, ранние описания предполагаемой эмфиземы включают заметки Т. Бонета по поводу состояния «объемных легких» в 1679 г. и Джованни Моргагни в 1769 г. по поводу легких, которые были «распухшими, в частности, за счет воздуха» [24]. Первое описание эмфиземы выполнено в 1721 г. Руйшем. Термин «бронхит» был предложен С. Badham в 1808
Резюме Хроническая обструктивная болезнь легких является одним из важнейших заболеваний в практике врача и исследователя современности. Широкая распространенность состояния, тяжесть заболевания, многообразие коморбидной патологии и множество системных эффектов приводят к неугасающему интересу исследователей к хронической обструктивной болезни легких. Исторически взгляды на это заболевание претерпевали множество изменений: трансформация терминологии и определений заболевания, эволюция взглядов по вопросам этиологии и патогенеза. Процесс изучения легочной патологии начался с момента становления медицинской науки, и интерес к данной проблеме не угасает по сегодняшний день.

Ключевые слова: хроническая обструктивная болезнь легких, классификация, история изучения.

\section{HISTORICAL ASPECTS OF THE STUDY OF CHRONIC OB- STRUCTIVE PULMONARY DISEASE}

\section{A.A. Bakina, Yu.Yu. Schegortsova, V.I. Pavlenko}

FSBEI HE the Amur state medical Academy of the Ministry of Public Health of Russia, Blagoveshchensk

Abstract Chronic obstructive pulmonary disease is one of the most important diseases in the practice of a doctor and a modern researcher. The wide prevalence of the condition, the severity of the disease, the variety of a comorbid pathology and a variety of systemic effects lead to a continuing interest in chronic obstructive pulmonary disease. Historically, the views on this disease have undergone many changes: the transformation of terminology and definitions of the disease, the evolution of views on the issues of etiology and pathogenesis. The process of studying the pulmonary pathology began with the formation of medical science, and the interest in this problem is not fading to the present day.

Key words: chronic obstructive pulmonary disease, classification, history of study. 
году. Одно из первых наиболее полноценных фундаментальных описаний везикулярной эмфиземы легких принадлежит Р. Лаэннеку (1826), который связывал увеличение наполненности легких воздухом с нарушением проходимости мелких бронхов [20]. В 1861 г. С. Rokitansky ввел термин «эмфизема», которая, по его мнению, является постоянным спутником хронического бронхита. Одно из наиболее полных описаний симптоматики эмфиземы легких принадлежит С. И. Боткину (1887), который впервые выделил в качестве особой ее формы острое обратимое перерастяжение легких. На различие между истинной эмфиземой легких, сопровождающейся «исчезновением» легочной ткани и вздутием легких, указывал так же Р. Вирхов (1888). Н. Loeschke (1911) подробно описал изменения альвеолярных стенок при эмфиземе легких: истончение, разрушение эластических волокон, редукцию капилляров.

Активному изучению ХОБЛ, нарушения легочного дыхания и иных проявлений этого заболевания в середине XIX века способствовали множественные открытия и создание новых методов обследования пациентов. Так, в 1842 г. Джон Хатчинсон изобрел спирометр, который дал возможность измерять жизненную емкость легких. Основные статьи Дж. Хатчинсона по спирометрии вышли в 1844-1852 гг. и содержали описание спирометра и методические указания по правильному использованию аппарата. В статьях были полученные автором материалы по спирометрии: Дж. Хатчинсон измерил статические объёмы у четырёх тысяч здоровых и больных людей. Исследуя здоровых людей, он сравнивал влияние на спирометрические объёмы пола, возраста, роста, веса, профессии. Названия статических объёмов и ёмкостей лёгких, которые были даны Дж. Хатчинсоном, не изменились и в наши дни. Однако спирометр Хатчинсона был способен измерять лишь объем, но не воздушный поток, что так важно для диагностики ХОБЛ. Середина XX века ознаменовалась новым пиком изучения ХОБЛ ввиду новых открытий, используемых в диагностике легочной патологии. В 1947 г. Б.Е. Вотчал для диагностики нарушений проходимости бронхиальных путей применил методику, состоящую в измерении объема форсированного выдоха после максимального вдоха и сравнении этой величины с объемом полного нефорсированного выдоха после максимального вдоха. Независимо от него в 1949 г. французский ученый Тиффно предложил подобный способ, отличающийся стандартным ограничением измерения объема форсированного выдоха - только за первую его секунду. В настоящее время обследования всех пациентов с ХОБЛ включают изучение данных показателей.
Хроническая обструктивная болезнь легких - относительно новое понятие, лишь в начале 1990-х годов вошедшее в практику отечественной медицины. В начале XX века в медицине для обозначения состояния часто использовались термины «пневмосклероз», «хроническая неспецифическая легочная чахотка» [11]. А за последние пятьдесят лет было предложено множество различных определений: «хронические неспецифические заболевания легких» (ХНЗЛ), «хронический обструктивный бронхит», «хроническая пневмония», «хронические обструктивные заболевания легких», «хроническая обструктивная болезнь» $[10,14,17,19]$. Из-за неполноценности выражения сущности патологии в названиях на XIII съезде терапевтов СССР в 1947 г. был предложен термин ХНЗЛ. В период начальных попыток внедрения концепции ХОБЛ в российскую медицину Н.В. Путов отмечал неприемлемость применения диагноза «обструктивная болезнь легких» для решения проблемы классификации заболеваний бронхолегочной системы [10]. Н.А. Ардаматский считал, что концепция ХНЗЛ и хронической пневмонии была несостоятельной ввиду отсутствия системности при попытке создания монического представления о сущности указанных патологий [1]. С середины 90-х годов XX века все ранее данные определения трансформировались в понятие "хронические обструктивные болезни легких», которое объединило хронический обструктивный бронхит, эмфизему легких, некоторые формы бронхиальной астмы, бронхоэктатическую болезнь, муковисцидоз и облитерирующий бронхиолит [13]. И лишь недавно возникло известное представителям практического здравоохранения название «хроническая обструктивная болезнь легких». На настоящий момент название «хроническая обструктивная болезнь легких» или ХОБЛ закрепилось в медицинской среде.

В патогенезе ХОБЛ огромная роль уделяется хроническому локальному и системному воспалению. Еще в 1838 г. С.J. Corrigan считал, что хроническое воспаление в легких и склеротические изменения легочной ткани мигрируют на бронхи, следствием чего является развитие хронического бронхита [3]. При патоморфологических исследованиях определяется гипертрофия гладкомышечных клеток бронхов и перибронхиальный фиброз, которые являются необратимыми элементами нарушения дыхания по обструктивному типу. Разрушение стенок альвеол ведет к развитию эмфиземы легких, так же легочная паренхима видоизменяется по типу пневмосклероза [22]. Пневмосклероз (греч. pneumon легкое + sklerosis уплотнение) - разрастание соединительной ткани легких в результате воспаления или дистрофии, следствием которого являются 
нарушение эластических свойств и газообменной функции в легочной ткани. Взгляды на развитие этого патоморфологического процесса у больных ХОБЛ изменялись на протяжении истории изучения заболевания. Так, в монографии 1963 года «Современное состояние учения о хроническом бронхите» под редакцией С.О. Невилл отмечалось, что выраженность фиброза бронхов значительно варьируется: фиброз представлен в виде диффузного процесса, или может быть тяжистым, интраальвеолярным, или интерстициальным, макро- или микроскопическим [8]. И.В. Давыдовский развивал идею пневмосклероза в виде «мускульного цирроза» ввиду регулярных дыхательных экскурсий [5]. 3.А. Гастева в монографии «Пневмофиброзы и эмфизема легких» (1965) указывает на вовлечение в процесс кровеносных и лимфатических сосудов легкихи нервов [4]. В 70-е годы XX века понятие «пневмосклероз» ассоциировалось с существовавшими представлениями о хронической пневмонии. В последующие годы интерес исследователей к изучению пневмосклероза при ХОБЛ угас и сконцентрировался на изучении эмфиземы легких. Во многом этот интерес был спровоцирован появлением компьютерной томографии, метод которой был предложен в 1972 году Годфри Хаунсфилдом и Алланом Кормаком, получившими за эту разработку Нобелевскую премию. Возникшая позднее компьютерная томография высокого разрешения (КТВР) позволила выделить новые фенотипы ХОБЛ: фенотип М (у пациента имеется эмфизема легких в сочетании с утолщением стенок бронхов), фенотип Е (наличие у больного эмфиземы легких без утолщения стенок бронхов), фенотип А (у пациента нет эмфиземы легких, а утолщение стенок бронхов может присутствовать или не присутствовать) [18]. J.Wiggins et al. (1990) на основании данных, полученных при выполнении КТВР, представили 8 видов комбинации идиопатического пульмонального фиброза и эмфиземы легких и выделили синдром комбинации пульмонального фиброза и эмфиземы (CPFE) [23]. Исследователи сконцентрировали внимание на изучении этих взаимоотношений.

Клиническая характеристика больных, страдающих ХОБЛ, соответствует данным R.S. Mitchell и G.F. Filleu, которые еще в 1964 г. выделили три группы больных: «с преобладанием кашля», "с преобладанием одышки» и "сочетанная с астмой». Позднее, в 1968 г., G.F. Filleu et al. определили, что по клиническим особенностям пациента с ХОБЛ можно отнести к одной из двух клинических групп: «розовые пыхтельщики» (pink puffers), у которых в клинике преобладала одышка, и «синие отечники» (blue bloaters), главным симптомом заболевания у которых являлся кашель [16]. Позднее указанным типам присвоили название «эмфизематозный» и «бронхитический». В настоящее время одним из наиболее известных исследований является обсервационное исследование ECLIPS по результатам которого был установлен еще один фенотип ХОБЛ - «с частыми обострениями». Поиск новых фенотипов на настоящий момент не окончен, исследователи предлагают к вниманию все новые и новые клинические фенотипы. Так, В.А. Капустина и С.И. Овчаренко предлагают выделить в отдельную группу фенотип ХОБЛ у женщин ввиду имеющихся особенностей течения заболевания в зависимости от пола [9]. Некоторые исследователи предлагают выделить вариант ХОБЛ с бронхиальной гиперреактивностью в отдельный фенотип, характеризующийся более тяжелым течением заболевания [12]. На современном этапе ХОБЛ рассматривается как заболевание с признаками поражения, как респираторного тракта, так и имеющее системные проявления, которые во многом обусловлены наличием системного воспаления $[6,7]$.

Таким образом, сложившиеся на настоящий момент представления о ХОБЛ нельзя считать законченными и логически завершенными. Остаются нерешенными вопросы, касающиеся этиологии, патогенеза, механизмов развития и особенностей течения коморбидной патологии, часто встречающейся у больных ХОБЛ. Требуют дальнейшего изучения аспекты течения болезни и значимости ее клинических проявлений. Дальнейшее изучение патологии позволит вести успешную профилактическую работу, контролировать течение заболевания и эффективно использовать терапевтические ресурсы для его лечения.

\section{Литература}

1. Ардаматский Н.А. Хроническое неспецифическое заболевание лѐгких как нозологическая единица // Терапевтический архив. 1991. № 12. C. $128-130$.

2. Барабанова E.H. GOLD (2017): что и почему изменилось в глобальной стратегии лечения хронической обструктивной болезни легких // Пульмонология. 2017. № 27 (2). С. 274-282.

3. Большая медицинская энциклопедия под ред. Н.А. Семашко. Москва, 1933.

4. Гастева 3.А., Нешель Е.В., Успенская В.Г. Пневмофиброз и эмфизема легких. Л. «Медицина». 1965. 207 c.

5. Давыдовский И.В. Общая патология человека. М.: Медицина. 1969.

6. Колосов В.П., Павленко В.И. Прогнозирование частоты обострения хронической обструктивной болезни легких, сочетанной с ишемиче- 
ской болезнью сердца // Бюллетень физиологии и патологии дыхания. 2012. Вып. 45. С. 35-37.

7. Кулик Е.Г., Павленко В.И., Нарышкина С.В. Ассоциация артериальной ригидности с маркерами дисфункции сосудистого эндотелия и системного воспаления при хронической обструктивной болезни легких // Бюллетень физиологии и патологии дыхания. 2018. Вып. 67. С. 31-36.

8. Невилл С.О. (ред.). Современное состояние учения о хроническом бронхите. М. 1963.

9. Овчаренко С.И., Капустина В.А. Хроническая обструктивная болезнь легких: особенности у женщин. Пульмонология 2009; 2. С. 102-112.

10. Путов Н.В., Федосеев Г.Б. (ред.). Руководство по пульмонологии. Л.: Медицина. 1984. 456 с., ил.

11. Рубель А.Н. Клиническая патология внутренних болезней. Л.: Издательство «Кубич». 1927. 229 c.

12. Трофименко И.Н., Черняк Б.А. Бронхиальная гиперреактивность как фенотипическая характеристика хронической обструктивной болезни легких. Пульмонология 2011; 4. С. 49-53.

13. Хронические обструктивные болезни легких. Под ред. А.Г. Чучалина. СПб; 1998. 512 с.

14. Чучалин А.Г. (ред.). Хроническая обструктивная болезнь легких. М.: Атмосфера. 2008.

15. Chuchalin A.G., Khaltaev N., Antonov N.S.et al. Chronic respiratory diseases and risk factors in 12 regions of the Russian Federation. Int J Chron Obstruct Pulmon Dis 2014; 9: 963-974.

16. Filleu G.F., Beckwitt H.J., Reeves J.T., Mitchell R.S. Oxygen transport in two clinical types. Am. J. Med. 1968; 44: 26-28.

17. Fishman A.P. One hundred years of chronic obstructive pulmonary disease. Am. J. Respir. Crit. Care Med. 2005; 171 (5): 941-948.

18. Fujimoto K., Kitaguchi Y., Kubo K., Honda T. Clinical analysis of chronic obstructive pulmonary disease phenotypes classified using highresolution computed tomography. Respirology 2006; 11 (6): 731-740.

19. Global initiative for chronic obstructive lung disease. Global strategy for the diagnosis, management and prevention of chronic obstructive pulmonary disease. NHLBI / WHO workshop Report. Last updated. 2011.

20. Laennec R.T. On pneumothoraxai des epanchenents aerrformes dans la canite pleurale. Paris. 1812:432-436.

21. Lozano R, Naghavi M, Foreman K. et al. Global and regional mortality from 235 causes of death for 20 age groups in 1990 and 2010: a systematic analysis for the Global Burden of Disease Study 2010. Lancet. 2012;380(9859):2095-128. DOI: 10.1016/S0140-6736(12)61728-0.

22. Salazar L.M., Herrera A.M. Fibrotic response of tissue remodeling in COPD. Lung 2011; 189 (2): 101-109.

23. Wiggins J., Strickland B., TurnerWarwick M. Combined cryptogenic fibrosing alveolitis and emphysema: the value of high resolution computed tomography in assessment. Respir. Med. 1990; 84 (5): 365-369.

24. Ziment, Irwin (1991). "History of the Treatment of Chronic Bronchitis». Respiration 58 (Suppl 1): 37-42. doi:10.1159/000195969. PMID 1925077.

Статья поступила в редакцию 10.01.2019

\section{Координаты для связи}

Бакина Анастасия Алексеевна, аспирант кафедры факультетской и поликлинической терапии ФГБОУ ВО Амурская ГМА Минздрава России. E-mail: anastasia_darchi@mail.ru

Щегорцова Юлия Юрьевна, аспирант кафедры факультетской и поликлинической терапии ФГБОУ ВО Амурская ГМА Минздрава России.

Павленко Валентина Ивановна, д. М. Н., профессор кафедры факультетской и поликлинической терапии ФГБОУ ВО Амурская ГМА Минздрава России.

Почтовый адрес ФГБОУ ВО Амурская ГМА Минздрава России: 675006 Амурская область, г. Благовещенск, ул. Горького, д. 95. E-mail: AmurSMA@AmurSMA.su, science.dep@ AmurSMA.su 